\title{
A PRÓSPERA ESTRATEXIA DUNHA POLÍTICA DE CLÚSTERS: A EXPERIENCIA
}

FRANCESA

Jean-Louis TRUEL

Profesor Asociado Université Paris Est Créteil, Vicepresidente do Cercle Kondratieff

Sergey K. VOLKOV

Doutor en Económicas, Profesor Asociado do

Departamento de "teoría mundial e teoría da economía", Volgograd State Technical

University (Russia)

\begin{abstract}
Resumo : A necesidade de reestruturar a economía nos países de Europa Central e Europa do Leste, así como noutras economías emerxentes ou economías en transición, deu lugar unha variedade de iniciativas de políticas públicas. Algunhas ideas para as políticas industriais de Rusia que promovían a innovación, pódense atopar na experiencia de Francia, especialmente na política orixinal de clústers que se estableceron nos últimos seis anos.

Palabras chave: clúster, política industrial, parques industriais, parques tecnolóxicos, incubadoras, sinerxía, desenvolvemento rexional

Abstract: The need to restructure the economy in Central and Eastern Europe countries, as well as in other emerging economies or economies in transition, has led to a variety of public policy initiatives. Whatever the official vocabulary, "Innovation" is a key aspect of these policies. Some ideas for Russia's industrial policy promoting innovation could be found in the French experience, especially in the original policy of clusters that has been implemented during the past six years.

Keywords: cluster, industrial policy, industrial parks, techno parks, incubators, synergy, regional development
\end{abstract}

\section{Diferentes funcionamentos dos clústers}

Os clústers, definidos como un conxunto de empresas independentes nunha determinada área xeográfica, son unha realidade antiga que se pode remontar á baixa Idade Media. O concepto moderno de clústers foi popularizado nos anos 1980, polos traballos de Michael Porter, entre outros. Durante a última década, esta noción foi revivida como ferramenta de políticas industriais en moitos países de Europa e Asia.

A principal característica dos clústers é que non son soamente unha suma de habilidades, financiamento público e privado, instalacións de inmobles, etc, senón que tratan de formar un ecosistema completo, integrando toda a cadea de valor dende a formación e investigación ata o acceso ao mercado.

Pódense identificar dous achegamentos diferentes aos clústers.

Os "clústers empresariais". Este modelo está moi estendido en Italia, o norte de Europa e, ata certo punto, en Alemaña. Normalmente son o resultado dun enfoque ascendente, iniciado por empresas dunha determinada situación xeográfica e de vez en cando adicadas a tecnoloxías específicas. Aportan unha completa gama de actividades e servizos específicos para os seus membros: redes, agrupacións de competencias, actividades educativas e formativas, servizos orientados á exportación, etc. Poden ou non estar asociados a parques industriais. A xestión do clúster está financiada polas cotas dos socios e por servizos pagados por eles, con pouco apoio público.

Os clústers de innovación "dependente de políticas". Esta organización de clústers é máis complexa e require un alto nivel de compromiso público a nivel nacional e rexional. Como cabe esperar, atópase en países cunha forte tradición industrial, a nivel estatal 
(Francia, Corea) ou a nivel rexional (Alemaña). Malia que hai diferenzas nacionais e rexionais, podemos destacar as seguintes características comúns:

- $\quad$ O enfoque tecnolóxico. A meirande parte destes clústers caracterízanse por certo grao de especialización que varía dun "clúster tecnolóxico" a outro.

- Financiamento público. O financiamento nacional e rexional adoitan representar do 40 ao $50 \%$ do total dos proxectos de I+D.

- Participación de centros de investigación públicos, autoridades locales, grandes corporacións e PEMEs e o fomento activo de cooperación de todas as organizacións en todos os niveles.

- A aportación de locais e instalacións. Cuando os clústers dependen de fortes organismos que xa existen, a construción de parques tecnolóxicos e industriais non son prioritarios, agás as incubadoras que se dirixen especificamente a start-ups e pequenas empresas. Porén, en ocasións os clústers aportan instalacións comúns a todos os seus socios, por exemplo, laboratorios de probas para proxectos en campos relacionados.

- Apoio organizativo. A diferenza con respecto aos "clústers empresariais" é o grao de participación das autoridades estatais e locais en manter organizacións permanentes de apoio cun forte financiamento público.

- Políticas públicas de compras. Un aspecto interesante é o uso de mercados públicos para axudar ás empresas a validar as súas innovacións e realizar a proba de concepto.

- Financiamento. Cada vez máis, formar parte do clúster considérase unha marca de calidade, que facilita o acceso ao financiamento público e ao privado. Estase creando financiamento específico mediante o investimento conxunto entre o Estado e os investidores privados.

- Desenvolvemento de cualificacións que se adapten aos requisitos das empresas mediante o sistema educativo.

Unha combinación de criterios xeográficos e industriais

En Francia, os "pôles de Compétitivité" crearonse no ano 2005. Agora hai 71 en todo o país, que abranguen a meirande parte da industria, incluído o sector financeiro (véxase o mapa no Anexo). O principio orixinal dos "pôles" (clústers) foi o de asociar empresas e centros públicos de investigación dunha mesma área xeográfica, que traballaban en temas parecidos. O Estado aporta financiamento para I+D e apoio organizativo, mentres que as rexións adícanse principalmente a tarefas organizativas. Posto que a meirande parte do financiamento provén do orzamento estatal, o proceso de certificación realízase a nivel nacional. Malia non é específico de Francia, os pôles poñen moito énfase na cooperación estrutural entre catro categorías de socios:

. Centros públicos de investigación e universidades

. Grandes empresas

. PEMES

. Autoridades públicas a nivel nacional, rexional e, en ocasións, local.

Programas de I+D

Ao principio, os "pôles" adicábanse principalmente a $\mathrm{I}+\mathrm{D}$, coa intención de racionalizar o investimento público e privado neste sector. Os programas de I+D representan a meirande parte do financiamento dos clústers: arredor de 450 millóns de 
euros por ano, máis outros 50 millóns de euros en beneficios fiscales específicos.Os proxectos están suxeitos a licitacións, polo xeral, tres por ano. Cada ano, arredor de 800 proxectos fináncianse con fondos públicos. Ademais do financiamento do Estado, pode haber financiamento rexional ou local para proxectos específicos, e tamén en ocasións, financiamento da UE. Sistematicamente, os "pôles" máis grandes de Francia -especializado en electrónica e informática- reciben unha media 75 millóns de euros en financiamento público (do Estados, da rexión Île de France e doutras autoridades locais), para un total duns 60 proxectos por ano. Os proxectos de I+D deben incluír empresas, preferentemente grandes e pequenas, e centros públicos de investigación. O número de participantes adoita oscilar entre 3 e 10.Os proxectos de I+D están cofinanciados por autoridades e axencias públicas e polas mesmas empresas. Para unha media de 1 euro de diñeiro público, as empresas aportan entre 2 e 2,50 euros.

\section{Organización do clúster, relacións entre os membros e estrutura diretiva}

A eficacia dun clúster depende en gran medida da súa organización e funcionamento. O problema xorde cando hai un ou máis socios que son "máis iguais ca outros": o organismo gobernamental, as grandes empresas, etc. A estrutura directiva debe mediar para chegar a acordos entre os intereses particulares de todos os socios do clúster.

Afiliación. Normalmente os clústers comezan cun número limitado de "socios fundacionais": autoridades nacionais e rexionais, universidades, laboratorios de investigación, grandes empresas, PEMEs. Durante a fase de desenvolvemento, vanse asociando novos membros ao clúster.

Cada un dos novos membros deben ser aprobados por un comité executivo do clúster que xulga se a estratexia do aspirante é compatible co obxectivo do clúster. Este proceso de aprobación é importante porque proporciona algún tipo de "etiqueta" aos membros do clúster.

Na maioría dos clústers, a cota mínima para todas as empresas pequenas e organizacións académicas é de 100 a 500 euros por ano. Outras empresas pagan en función do seu tamaño. Os socios teñen acceso gratuíto á meirande parte do apoio organizativo e servizos proporcionados polo clúster.

Estrutura directiva. Os "pôles" franceses teñen carácter de organizacións sen ánimo de lucro (o estatus específico en Francia para "Associations Loi 1901"). Os socios elixen a un comité directivo e cada categoría (organismo público, universidades e centros de investigación, grandes empresas, PEMEs) ten dereito a un determinado número de directores de modo que haxa un equilibrio entre todos os representantes. O comité directivo elixe a un comité executivo, que define a estratexia do clúster: as súas principais áreas de actuación, aprobación de proxectos de I+D para presentar a licitacións, definición dun rango de servizos de apoio aos socios, solicitudes de apoio público na área de formación académica, etc. Os directores e os membros do comité executivo están nomeados polas organizacións dos socios dos clústers e teñen carácter voluntario.

Toma de decisións e equilibrio entre os socios. Os socios do clúster poden ter diferentes intereses para definir as súas prioridades estratéxicas. Ao haber representantes de todas as partes que participan normalmente, evítase que as decisións se tomen favorecendo intereses privados. Na práctica, os clústers son eficaces se os socios grandes amosan un forte interese en participar en programas comúns e sinerxías de desenvolvemento.

Organización de apoio. Unha estrutura permanente de apoio achega coordinación e servizos diarios aos socios. Os grandes clústers chegan a ter un persoal de ata 20 empregados permanentes dirixidos por un director xeral. Esta organización axuda a 
definir as sinerxías internas do clúster e proporcionar apoio ás empresas máis pequenas. O persoal adoita estar formado por especialistas con experiencia no sector.

O financiamento estatal para os orzamento de funcionamento dos clústers é de uns 12 millóns de euros anuais. A isto hai que engadir o financiamento rexional e privado, principalmente das cotas de afiliación. En total, o orzamento de funcionamento para os "pôles" máis grandes é de uns 3 millóns de euros.

\section{A participación das PEMEs}

En total 7200 empresas son socias dalgún clúster (moitas delas pertencen a varios clústers). As PEMEs representan o $80 \%$ do número total de empresas asociadas. Unha tendencia significativa foi o aumento do número de PEMEs entre os socios, e tamén un cambio de enfoque. En Systematic, que se consideraba un clúster formado principalmente por "grandes empresas" con 35 PEMEs no ano 2005, conta agora con 350 PEMEs fronte a 150 grandes empresas. No 2005 as PEMEs recibiron o 8\% do financiamento público aportado aos proxectos de Systematic fronte ao $40 \%$ para grandes empresas e o $52 \%$ para laboratorios públicos. No ano 2009 a proporción foi do 35\% para PEMEs fronte ao $25 \%$ para grandes empresas.

O cambio tamén é moi cualitativo. Os clústers teñen tendencia a ofrecer unha gama moi ampla de servizos ás PEMEs afiliadas:

- Apoio empresarial, especialmente con respecto aos socios máis grandes do clúster (véxase abaixo)

- Apoio para a procura de financiamento: formación en "como presentar un plan empresarial atractivo", reunións con investidores, etc. Posto que a afiliación ao clúster depende da aprobación do comité, os investidores contan cun primeiro nivel de lexitimidade. Outros mecanismos de financiamento público -financiamento para I+D xa que o clúster forma parte dun avanzado sistema de financiamento público en Franciatamén favorecen aos socios dos "pôles" porque lles proporciona unha "marca".

- Apoio de márketing mediante actos colectivos.

- Rede de contactos. Hai moitos eventos organizados especialmente para as PEMEs. Por exemplo, hai PEMEs adicadas a reunións sobre temas como o financiamento público, propiedade intelectual, desenvolvemento internacional, recursos humanos, etc. Isto permite que las empresas socias teñan información de expertos dos temas, e lles permite intercambiar as súas experiencias.

- Desenvolvemento internacional. Moitos clústers organizan accións colectivas no estranxeiro para axudar aos seus socios a construír colaboracións noutros países. Partindo de colaboracións de tipo técnico, estas misións estanse convertendo cada vez máis de tipo comercial.

Cabe destacar que estes servizos normalmente están promovidos e parcialmente financiados polas autoridades locais e rexionais.

\section{Parques industriais, parques tecnolóxicos e incubadoras}

Na meirande parte dos casos, non hai parques industriais específicos construídos especialmente para os "pôles", malia que algúns poden estar asociados a eles. Porén, hay algunhas excepcións significativas:

Sophia Antipolis, que se creou hai 40 anos preto de Niza e é o maior "Technopôle" de Francia. Conta con 30.000 traballadores en 1.400 empresas ${ }^{1}$. Sophia Antipolis especialízase en informática e telecomunicacións -un dos maiores clústers franceses de

1 Amadeus, Schneider Electric, Hewlett-Packard, Thales, France Télécom, Bayer, Legrand, Air France, Siemens AG, NXP, SAP, Accenture, Toyota... 
informática (SCS) está situado alí-, ciencias da saúde, enerxía, xestión da auga, desenvolvemento sostible. Tamén hai 4.500 alunos e investigadores en sucursais dos centros de investigación e universidades máis pretixiosos de Francia² ${ }^{2}$ O technopôle está xestionado como unha organización sen ánimo de lucro, baixo estritas restricións urbanísticas.

Cando se creou Sophia Antipolis, foi unha verdadeira innovación en Francia. A maiores do seu grande impulso, beneficiouse da súa proximidade a dous grandes centros de investigación: IBM en La Gaude e Texas Instruments, preto de Niza. Evidentemente, a situación na "Côte d'Azur" axudou moito á súa promoción. Nos anos 1990, perdeu algo de atractivo: estaba alonxado doutros centros de innovación en Francia e os elevados prezos das vivendas fixo que a súa situación interesara menos. A nova política de clústers en Francia, co apoio público que implicou, deulle un novo impulso a Sophia Antipolis.

Innovalley. Situado preto de Grenoble, este parque tecnolóxico agrupa a 310 empresas (como Atos Origin, Cap Gemini, Schneider Electric) cun total de 9.000 traballadores. Tamén está asociado a empresas e centros de investigación (HewlettPackard, A Autoridade de Enerxía Atómica - CEA) situados na zona. Especialízase en informática, telecomunicacións e máis recentemente en biotecnoloxía. Innovalley tamén conta con dúas universidades de prestixio. Moitas das empresas e centros de investigación son socios dos clústers "Minalogic" (de tecnoloxías micro e nano) e "Tenerdis" (tecnoloxías para novas enerxías). Innovalley, xunto con outros centros de investigación e empresas innovadoras situadas na zona de Grenoble déronlle á rexión unha imaxe positiva de centro de altas tecnoloxías. A proximidade ás estacións de esquí tamén contribuíron a facelo máis atractivo.

Hai un novo campus científico e de investigación planificado para o sur de París, na meseta de Saclay. Estará asociado a varios "pôles" da rexión de París, porén hai moitos problemas para o seu establecemento.

A meirande parte dos clústers franceses fundaron ou apoiaron ás "incubadoras". Estas incubadoras diríxense a empresas start-ups e proporciónanlles infraestruturas e asesoramento para que poidan iniciar os seus proxectos cuns gastos de operación máis reducidos.

\section{Creación de sinerxías de mercado}

A este aspecto adoitáselle prestar menos atención cas sinerxías en I+D na definición de "clústers dirixidos ás políticas". Porén, a experiencia internacional amosa que as sinerxías de mercado aportan algúns dos resultados máis positivos das políticas dos clústers. Un efecto significativo dunha mellor estruturación dos "pôles" franceses é a importancia que se lle dan ás sinerxías entre os socios do clúster. Estas sinerxías xorden naturalmente cando se traballa en proxectos de I+D comúns. Porén a tendencia é a crear unha rede de empresas que colaboran en moitas outras áreas aproveitando para se complementaren.

As grandes empresas socias dos "pôles" organizan presentacións dos seus requisitos para atopar "provedores tecnolóxicos", é dicir, pequenas e medianas empresas con tecnoloxía innovadora. A Autoridade de Enerxía Atómica Francesa (CEA), que cobre moitos campos da electrónica e software integrado, tamén está apoiando a estes provedores tecnolóxicos en gran medida.

Debido á crecente interacción entre as tecnoloxías en áreas anteriormente separadas, hai unha forte tendencia a construír sinerxías entre os clústers.

2 CNRS, INSERM, I3S, LEAT, INRIA, INRA, Mines ParisTech, Institut Eurécom (Télécom Paris), CNAM... O Consorcio Worldwide Web tamén ten a súa sede europea en Sophia. 
Establecéronse moitos grupos de traballo entre os clústers. Os exemplos máis evidentes son a colaboración entre los clústers de informática e unha ampla gama doutros clústers: a industria da saúde e farmacéutica; desenvolvemento ambiental e aforro de enerxía; a industria do automóbil e transporte; finanzas, mesmo a industria alimentaria e a mecánica. As nanotecnoloxías son outra área na que os clústers especializados poden desenvolver interaccións con toda unha gama de clústers doutras industrias.

Tamén cabe mencionar, por unha banda, as colaboracións entre os clústers da química e os materiais, e por outra, unha gama de clústers industriais. Algúns exemplos deste último son as aeronaves e o espazo, automoción e transporte, farmacia, desenvolvemento do medio ambiente e planificación urbanística e deseño.

\section{Compras públicas}

Outro nivel de sinerxías consiste en políticas públicas de compras. Foron unha das principais ferramentas de política industrial en moitos países, especialmente en industrias de alta tecnoloxía. No caso das tecnoloxías máis avanzadas, reduce os riscos e aporta financiamento a provedores con maior eficacia cas subvencións ou vantaxes fiscais ${ }^{3}$. Este mecanismo tamén é moi eficiente para dar a coñecer a maior escala a texnoloxías máis maduras, e pódese implantar a un nivel local e rexional4. Outra opción, máis específica das tecnoloxías desenvolvidas por empresas socias dos clústers, é a de implantar proxectos piloto innovadores a nivel local ou rexional. Isto permítelle aos provedores aportar a "proba do concepto" e acadar unha primeira referencia para a explotación no mercado. Isto é, por exemplo, o que está facendo a rexión de París coa súa organización "Paris Region Lab", que fomenta as tecnoloxías desenvolvidas nos clústers e ten un impacto na mobilidade, a planificación urbanística, o transporte e a cultura.

\section{Vantaxes dos clústers estruturados e primeiros resultados en Francia}

Os clústers con políticas estruturadas ofrecen moitas vantaxes.

Aportan un marco para políticas públicas en canto ao desenvolvemento económico, e tamén á política de educación e investigación.

Proporcionan un ambiente favorable ás capacidades de desenvolvemento tecnolóxico: organizan colaboracións entre centros públicos de investigación, autoridades locais, grandes corporacións e PEMEs.

Proporcionan servizos para as empresas socias, especialmente start-ups e PEMEs.

Fortalecen as empresas existentes.

Conseguen visibilidade nacional e internacional.

No caso de Francia, a política de clústers deu resultados moi positivos.

Os programas de I+D permitiron ás empresas afiliadas aumentar a súa vantaxe tecnolóxica. Dende 2006, financiáronse 3.000 proxectos, 700 dos cales xa concluíron; 0 $50 \%$ destes proxectos deron lugar a novos produtos ou procesos de produción.

Porén, o resultado máis interesante é que a meirande parte dos clústers axudaron a crear un novo ambiente no que as empresas innovadoras se beneficiaron de apoio e sinerxías que non serían posibles doutro xeito. Estímase que estes clústers permitiron ou

\footnotetext{
3 Este tipo de política pódese considerar un dos factores chave do éxito da industria norteamericana en áreas como a defensa, a electrónica e o espazo. Outro factor é a obriga de destinar unha parte das compras públicas ás PEMEs.

4 Por exemplo, moitos estados dos Estados Unidos financiaron as redes Wi-Fi nas cidades, campus universitarios e parques tecnolóxicos. Combina a vantaxe de proporcionar mercados a empresas locais e aportar unha infraestrutura de alto nivel a outras industrias.
} 
facilitaron a creación dunhas 1.000 empresas, é dicir, o 15\% do número total de socios dos "pôles".

A política de clústers conseguiu aumentar a colaboración entre as autoridades locais e os socios privados.

A acción das autoridades rexionais desempeñaron claramente un importante papel e, en moitos casos, axudou a cambiar a imaxe de áreas industriais antes en declive.

Polo tanto, os clústers débense considerar elementos dun ecosistema favorable máis cunha sinxela ferramenta de financiamento, como adoitaban ser ao principio.

\section{A política de clústers en Rusia: tendencias actuais}

A política de clústers estase facendo popular como práctica de xestión estratéxica nos territorios rusos. Neste país, dende o ano 2008, cada vez máis escoitase o termo "clúster" e "política de clúster" como é o caso de discursos dos oficiais do goberno e nos medios de comunicación [15, p. 87]. Os mecanismos e as formas do funcionamento dos clústers na organización da economía do espazo converteuse na principal corrente na axenda científica da Rusia moderna. Nembargantes, malia a popularidade da estratexia de clústers, o marco metodolóxico aínda está en fase inicial.

Non hai exemplos de implantacións de políticas de clústers con éxito a nivel territorial nas rexións rusas. O único clúster activo en Rusia son os clústers de montaña e costa dos Xogos Olímpicos de Inverno de Sochi. As localizacións das Olimpíadas de Sochi de 2014 formaron dous clústers: o de costa e o de montaña. O clúster de costa está situado no distrito Adler de Sochi e o de montaña preto da vila de Krasnaya Polyana.

Os clústers de costa e montaña están interconectados por novos enlaces por estrada e ferrocarril, que os une á nova terminal do aeroporto e un complexo de estacións de ferrocarril chave na rexión.

Os obxectos máis significativos do Clúster de Costa e, particularmente do parque do Vale de Imereti e as súas proximidades son:

1. O Estadio Central "Fischt";

2. O centro cuberto de patinaxe "Adler Arena";

3. A gran pista de xeo para hockey sobre xeo "Large";

4. O edificio que hospeda as dependencias do Comité Organizativo de "Sochi 2014" en Imereti lowland "Itera";

5. O Hotel Radisson Blu

6. A estación "Olympic Park";

7. O Palacio de Xeo para competicións de patinaxe artística e a pequena pista "Iceberg";

8. O Curling olímpico "disco";

9. A principal vila olímpica "Juicy";

10. O paseo marítimo Imereti, que forma parte das fortificacións costeiras de Imereti lowland;

11. O principal centro para medios de comunicación;

12. Varios hoteis con todo incluído e apart-hoteis;

13. As instalacións do Parque de Sochi;

14. As instalacións do complexo de Fórmula 1;

15. A estación de enerxía térmica de Adler;

16. O territorio do Parque Ornitolóxico.

As instalacións deportivas no clúster de montaña en Krasnaya Polyana inclúen:

- "Laura" - o campo para esquí de fondo e biatlón;

- "Rose Farm" - un centro de esquí; 
- "Rose Farm" - un parque para deportes extremos;

- "Sledge" - centro de Luge;

- "Russian Hills" - complexo para salto.

A organización e acollida dos Xogos Olímpicos e Paralímpicos en Sochi constituiu o proxecto socioeconómico más ambicioso (caro) da historia moderna de Rusia. Por exemplo, en abril de 2013 Vladimir Putin revelou as seguintes cifras "oficiais": un orzamento federal para as Olimpíadas de 99.000 millóns de rublos e houbo que pedir empréstitos de 144.000 millóns de rublos que suman un total duns 243.000 millóns de rublos. Estas cantidades, segundo o presidente, serviron para dúas vilas de medios de comunicación, 14 instalacións deportivas e 22 instalacións de seguridade. Non procede debater aquí o lado escuro desde megaproxecto, porén, segundo numerosos expertos e analistas nacionais e estranxeiros, os custos informais para a organización e montaxe dos Xogos Olímpicos é moito maior cos datos oficiais. O valor dos Xogos Olímpicos para a imaxe do país é difícil de calcular, xa que axudou a aumentar o nivel de lealdade non só dos cidadáns rusos, senón tamén da comunidade internacional. Ademais, tamén se conseguiron os seguintes aspectos positivos:

1.- Maiores investimentos. Actualmente, na rexión de Krasnodar realizáronse 225 proxectos de investimento por valor de máis de 941.000 millóns de rublos con prazos de finalización ata o 2015. Os ingresos fiscais en todos os niveis do orzamento estímanse en 60.100 millóns de rublos.

2.-Desenvolvemento de infraestruturas. Os Xogos Olímpicos sempre teñen un impacto positivo na rede de infraestruturas da rexión anfitrioa: hoteis, instalacións deportivas, estradas e ferrocarrís. Os Xogos Olímpicos de Inverno de 2014 non son unha excepción: no 2013, a rexión de Krasnodar foi a segunda do país en canto ao número de novas propiedades. Ademais, en preparación para as Olimpíadas en Sochi, construíronse $350 \mathrm{~km}$ de estradas e pontes novas.

3.- 0 crecemento do emprego. Durante os últimos anos creáronse 560.000 novos postos de traballo en Sochi. No ano 2013, a cidade tivo a taxa de desemprego máis baixa de Rusia con só un 0,17\%.

4.- 0 desenvolvemento de pequenas e medianas empresas. A venda de produtos co símbolo das Olimpíadas de Sochi foron as máis ambiciosas da historia dos Xogos Olímpicos. Lanzáronse 5.000 artigos de recordo, dende prendas deportivas ata moedas, selos e incluso artigos para mascotas. A venda de peluches da mascota dos xogos olímpicos superou as 3,6 millóns de copias. Os ingresos totais das vendas olímpicas por empresas titulares de licenzas foron de máis de 500 millóns de dólares.

5.- 0 desenvolvemento dos deportes de inverno en Rusia. Os Xogos Olímpicos e Paralímpicos forman unha importante e moderna base técnica para os principais países do mundo e continuará, esperemos, a ser usada polos atletas rusos.

Na etapa actual, as rexións rusas non teñen présa por aproveitar a experiencia de éxito da economía de clústers do estranxeiro. Ata onde a política de clústers se proclama como prioritaria, o impacto non se acaba por detectar. Mentres, limítanse a establecer os clústers que implantar no territorio (ou mellor dito, as empresas de industrias controladas), os que poden "crecer" (complementando enlaces que faltan) e o que pode ocorrer no futuro. En ocasións os documentos conceptuais amosan a dirección das políticas de clúster e a variedade de actividades, os proxectos de clúster comezados que apoian iniciativas de clústers. Nembargantes, a actual política de clústers das rexións rusas (con raras excepcións) só teñen unha natureza declarativa, sen que haxa un desexo para a implantación real de mecanismos nas áreas de actividade económica e produtiva.

Algunhas recomendacións para Rusia 
En base ao estudo da experiencia francesa, podemos propoñer algunhas recomendacións para Rusia en canto á implantación de iniciativas de clústers:

- o proceso que inicia clústers industriais territoriais debe partir das industrias, mentres que o apoio organizativo e financeiro debe ser implantado por conta do Estado;

- o goberno debe desempeñar un papel protagonista no proceso de formación e desenvolvemento da infraestrutura do clúster;

- fai falta cambiar a atención dende as industrias de apoio ás tecnoloxías de apoio, competencias chave e o desenvolvemento de aplicacións;

- é necesario sincronizar a política de clústers con outras áreas de desenvolvemento socioeconómico do territorio;

- hai que apostar polas pequenas e medianas empresas como "pilares" do clúster;

- é necesario o desenvolvemento de preferencias financeiras, económicas e legais para os socios do clúster.

A metodoloxía e as políticas de ferramentas básicas de clúster aínda están na súa infancia, o cal complica enormemente a implantación de mecanismos prácticos para establecer iniciativas de clústers. O déficit de exemplos empíricos de proxectos de éxito ou fracasados na implantación de iniciativas de clústers obstacularizan o eficaz desenvolvemento de bases industriais e tecnolóxicas non só das rexións individuais, senón tamén de todo o país.

\section{Reference list}

Bekele, G. and R. Jackson (2007). Theoretical Perspectives on Industry Clusters. West Virginia University Research Paper 2006-7.

European Commission (2007a) A lead market initiative for Europe, Communication COM (2007) 860

European Commission (2007b) Innovation Clusters in Europe: A statistical analysis and overview of current policy support, Europe INNOVA / PRO INNO Europe paper $\mathrm{N}^{\circ} 5$, Directorate-General Enterprise and Industry report.

Humphrey, J. and H. Schmitz (1996). The Triple C Approach to Local Industrial Policy.' In World Development. Vol. 24, No. 12, pp. 1859-1877.

Ketels, C. and Ö. Sölvell. (2005). EU Clusters in the EU-10 New Member Countries. Europe Innova Cluster Mapping Report.

Ketels, C.; Lindqvist, G. and Ö. Sölvell (2006). Cluster Initiatives in Developing and Transition Economies. Center for Strategy and Competitiveness Stockholm.

Maguire, K. and A. Davies (2007). Competitive Regional Clusters and National Policy Approaches. OECD Review of Regional Innovation.

Malsagov, A.I. (2012) Klasternyj podxod v regionalnoj politike. Humanities and socialeconomic sciences. №1, pp. 82-86.

Porter, M. (1979). On Competition. The Harvard Business Review Book Series.

Porter, M. (1990). The Competitive Advantage of Nations. New York: Basic Books.

Porter, M.; Ketels, C. and M. Delgado (2007). The Microeconomic Foundations of Prosperity: Findings from the Business Competitiveness Index. In World Economic Forum (2007). The Global Competitiveness Report 2007-08.

Schmitz, H. and K. Nadvi (1999). 'Clustering and Industrialization.' In World Development. Special Issue, Vol. 27, No. 9, September 1999.

Sölvell, Ö.; Lindqvist, G. and C. Ketels (2003). The Cluster Initiative Greenbook. The Competitiveness Institute (TCI). September 2003.

Tarasenko, V.V. (2013) Issledovanie territorialnyx klasterov: sociologicheskij podxod. Vestnik Rossijskogo universiteta druzhby narodov. Seriya: Sociologiya. № 2., pp. 13-20. 
Tarasenko, V.V. (2011) Strategii razvitiya territirialnyx klasterov. Economic strategies. № 11 (97), pp. 82-94.

\section{Anexo: os "pôles de compétitivité" franceses}

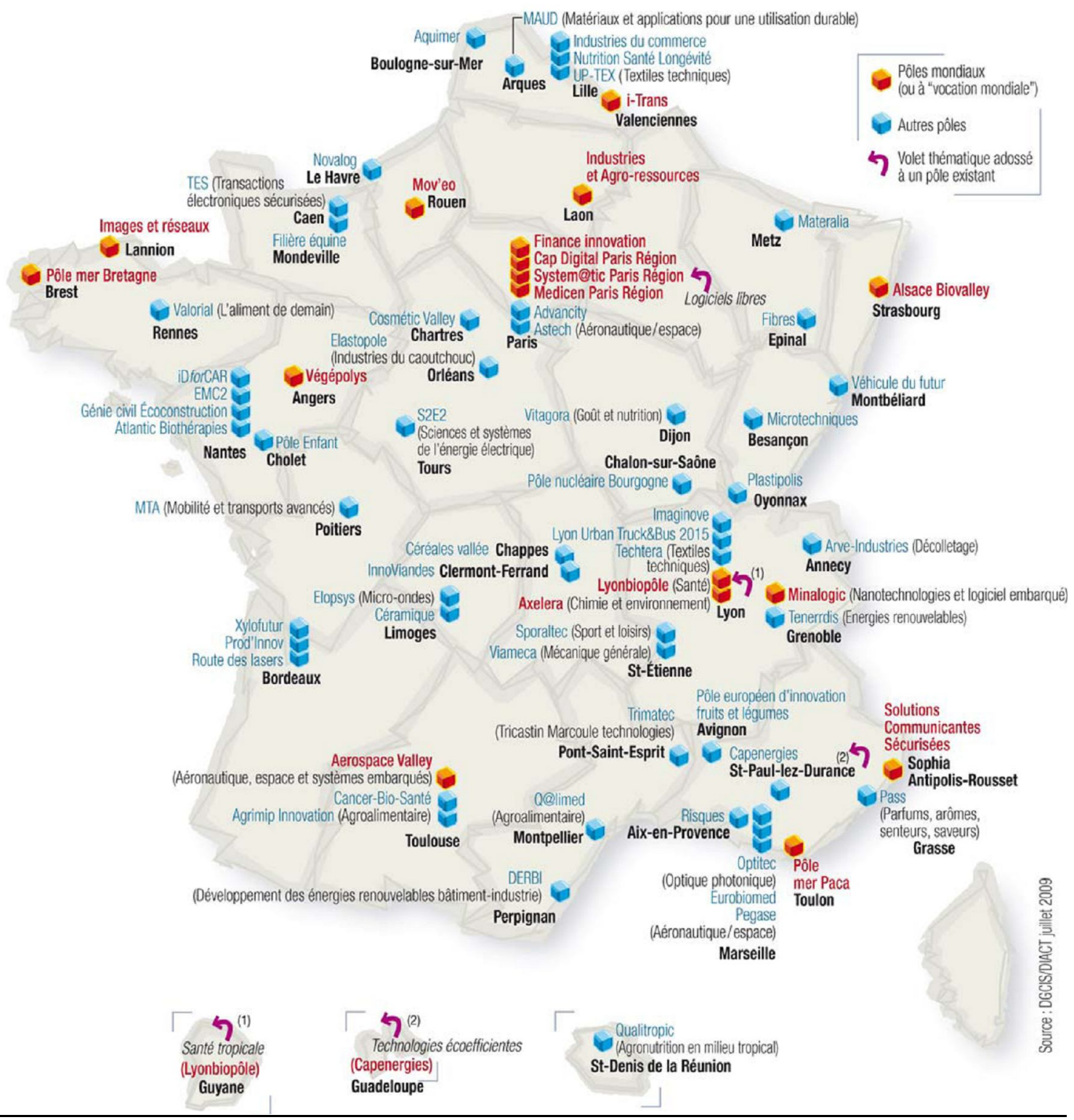

Revista Galega de Economia: http:// https:/ ideas.repec.org/ s/ sdo/ regaechtml http:/ / www.usc.es/ econo/ RGE/ benvidag.htm 